\title{
Nitrogen speciation and solubility in silicate melts and fluids
}

\author{
FABIEN BERNADOU ${ }^{1}$, ANETA SLODCZYK ${ }^{2}$, EVELYN \\ FÜRI $^{3}$, FABRICE GAILLARD ${ }^{4}$, YVES MARROCCHI ${ }^{5}$ AND \\ AURÉLIEN CANIZARES ${ }^{6}$
}

${ }^{1}$ Université d'Orléans

${ }^{2}$ ISTO

${ }^{3}$ Université de Lorraine/CNRS

${ }^{4}$ Institut des Sciences de la Terre d'Orléans

${ }^{5}$ CRPG, CNRS-Université Lorraine

${ }^{6}$ Cemhti Orléans

Presenting Author: fabien.bernadou@cnrs-orleans.fr

Nitrogen is the most abundant element in Earth's atmosphere and is a major actor in surficial biogeochemical cycles. Yet, its involvement in deep geochemical cycles, its mantle abundances, and the timing and magnitude of its degassing from the planetary interior to the atmosphere remain unclear. Here, we investigate magmatic degassing of nitrogen using high-pressure hightemperature experimentation in conjunction with vibrational and mass spectrometry. The aim is to develop a thermodynamic model defining both nitrogen solubility and speciation in silicate melts and fluids.

Most studies emphasize that the nitrogen solubility in silicate melts is very sensitive to the nitrogen and oxygen fugacities $\left(\mathrm{fN}_{2}\right.$, $\mathrm{fO}_{2}$ ). Three main nitrogen species have been described in silicate melts: $\mathrm{N}^{3-}$ and $\mathrm{NH}_{3}$ dominant under reduced conditions (i.e. $<\mathrm{IW}=2$ ) vs. $\mathrm{N}_{2}$ in more oxidized melts. However, the speciation of nitrogen in the equilibrium fluid is poorly understood. Several ex-situ studies attempted to determine the nitrogen speciation in fluid phase under such magmatic conditions in N-rich fluid systems at high pressure. Nowadays, the majority of the N-rich fluid studies work on the N-O-H system. Nitrogen speciation in this kind of fluid mainly take the form of $\mathrm{NH}_{\mathrm{x}}$ and $\mathrm{N}_{2}$ and seems to be strongly correlated with parameters of $\mathrm{fO}_{2}$ and nitrogen partial pressure.

Here we will present you both results on silicate melt and Nrich fluid. For the part on the silicate melt we will present results on solubility of nitrogen as a function of the variation of different parameters such as pressure (from $1 \mathrm{kbar}$ to $10 \mathrm{kbar}$ ) or $\mathrm{fO}_{2}$ (from IW+2 to IW-4). We will then discuss the parametrization of a nitrogen solubility model in silicate melt as a function of $\mathrm{P}$ $\mathrm{T}-\mathrm{fO}_{2}$. Lastly, for the part on the N-rich fluid we will discuss preliminary results of the in-situ study of N-rich fluids carried out at ISTO (Orleans) with an emphasis on temperature and pressure parameters by comparing our results with those of the study of Chen et al., 2019.

[1] Goldschmidt, Chen et al (2019), Chemical Geology, 51-57. 